\title{
Antecedents and outcomes of ERP implementation success
}

\author{
Prodromos Chatzoglou \\ Democritus University of Thrace, \\ Department of Production and \\ Management Engineering, \\ Vasillisis Sofias 12, 67100, \\ Xanthi, Greece \\ Email: pchatzog@pme.duth.gr
}

\author{
Dimitrios Chatzoudes \\ Democritus University of Thrace, \\ Department of Production and \\ Management Engineering, \\ Vasillisis Sofias 12, 67100, \\ Xanthi, Greece \\ Email: dchatzoudes@yahoo.gr
}

\author{
Georgia Apostolopoulou \\ Hellenic Open University, \\ School Of Social Sciences, \\ Parodos Aristotelous 18, 26335, \\ Patra, Greece \\ Email: geapostolo84@gmail.com
}

\begin{abstract}
Enterprise Resource Planning (ERP) systems have established a reputation in the world of business as indispensables tools that integrate all departments and functions across a company into a single computer system. However, implementing an ERP system does not always result in enhanced organizational performance. In order to ensure successful implementation, companies should study the critical factors having an impact on the whole procedure. In this context, the present study proceeds in developing and testing an original conceptual framework (research model), which explores the factors having an impact on ERP implementation success (internal environment, technology-related issues, implementation team, end-users), as well as the impact of the implementation itself on organisational performance. The proposed conceptual framework was tested, using a newlydeveloped structured questionnaire, in a sample of 204 Greek companies that have already implemented an ERP system. The Structural Equation Modelling (SEM) technique was used in order to test the research hypotheses.
\end{abstract}

\section{INTRODUCTION}

$\mathrm{T}$ HE explosive growth of Information and Communication Technologies (ICTs) (Information Systems, Enterprise Application Systems, Internet Technologies) has influenced, to a great extent, the way modern organizations operate in the business environment [1] [2]. Technological advances make information easily accessible, providing greater awareness of international economic opportunities [3].

Enterprise Resource Planning (ERP) systems are software systems which can be customized to integrate the business processes of a company, in such a way, that they are visible and accessible by the management in real-time [4]. An ERP system, designed to serve the modern sophisticated management, enables its users to coordinate key business practices across functions more efficiently, collect corporate data more holistically and offer optimal control over the operations of the organisation [5].

When an ERP system is successfully implemented, it promises to manage and integrate all business processes and functions within an organization [6] [7]. The integration, brought by ERP implementation, helps organizations to increase

This work was not supported by any organization. and improve their overall market position, in order to gain competitiveness in a rapidly changing business environment [8]. It also helps different divisions share data and knowledge, reduce costs and improve management of business processes [9] [10].

Due to the potential benefits of ERP systems, most of the organizations invested both time and money in their implementation [11]. However, ERPs have a reputation of costing a lot of money and providing limited results [10]. Some of the causes, cited in the relevant literature, for failed ERP projects include: poor project management planning, lack of business management support, unexpected return on investments, insufficient education and training, and, finally, weakness to redesign business processes [12] [13] [14].

Successful ERP implementation is quite valuable to many organizations, as it provides with numerous benefits. This explains why an ERP system is generally considered to be a vital component for enhancing organizational performance [15] [16] [17] [18] [19] [20] [21].

The ERP literature includes various studies investigating the factors having an impact on the effective implementation of ERP systems [8] [22]. On the other hand, there are fewer studies examining the impact of ERPs on different measures of business success [5] [15] [21] [23]. Despite that, the literature review analysis that has been conducted, failed to identify any empirical studies adopting a multidimensional approach, incorporating both antecedents and outcomes.

The present study aspires to bridge that gap in the relevant literature, developing and testing a threedimensional conceptual framework (research model). More specifically, the first dimension includes the antecedents of ERP successful implementation (internal environment, technology-related issues, implementation team, end-users), the second dimension the implementation itself (information quality, system quality, service quality), while the third dimension includes three measures of organisational performance (internal efficiency, competitiveness, profitability).

Therefore, the main objective of the study is to identify the factors that drive ERP implementation success, and, consequently, measure the effect of implementation on organization performance. The measurement of each of the 
three dimensions is being conducted with the use of multiple measures (sub-factors).

The examination of the proposed conceptual framework was made with the use of a newly-developed structured questionnaire that was distributed to a group of Greek companies. The Structural Equation Modelling (SEM) technique was used in order to test the research hypotheses. The present study is empirical (it is based on primary data), explanatory (examines cause and effect relationships), deductive (tests research hypotheses) and quantitative (analyses quantitative data collected with the use of a structured questionnaire). Its results may be useful for managers, business analysts and IT analysts in dealing with the implementation of ERP systems.

The following section includes a review of the literature; section three presents the conceptual framework of the study, while section four includes the research methodology. Results and conclusions are discussed in sections 5 and 6 respectively.

\section{LITERATURE REVIEW}

An ERP system entails long-term application processes (strategic level) and short-term applications (operational level). As a consequence, it is a given fact that ERP implementation cannot be imposed overnight [24]. On the contrary, it involves constant modifications and gradual implementation, so that in the end it will meet specific needs and bring out desirable end results [25].

Several studies have attempted to describe the critical success factors associated with the implementation and final use of ERP systems [24]. For example, Hong and Kim [26] identified the fit between the ERP system and the organizational climate as a crucial predictor of implementation success. They, also, argued that ERP implementation affects most of the business processes, and influences users directly [26].

Since ERP implementation will, most likely, affect the whole organization, reengineering of business processes is also required for business success [14]. Al-Mashari, AlMudimigh and Zairi [14] developed a theoretically and practically grounded taxonomy of ERP critical success factors. They argued that critical factors should gap the bridge between ERP implementation and (a) business processes, (b) Information Technology (IT), (c) structure, (d) culture and management systems, and (e) strategy.

Motwani, Subramanian and Gopalakrishna [27] conducted a comparative case study of four firms that implemented an ERP system, arguing that an evolutionary implementation process, which is supported by careful change management, network relationships and cultural readiness, can lead to successful implementation. Somers and Nelson [28] listed 22 critical success factors and categorized them according to the stage of implementation. They argued that package selection is among the most significant factors.
Ram, Wu and Tagg [29] built a conceptual model exploring the impact of two critical success factors (training and education, and system integration activities) on ERP implementation effectiveness.

Ifinedo and Nahar [30] found out that system quality and information quality are considered as the most important dimensions in the assessment of ERP success. Similarly, Chien and Tsaur [31] concluded that system quality, service quality and information quality seem to be the most important factors when implementing an ERP system. Similar lists of factors have been proposed by several other authors [10] [32].

Esteves and Pastor [33] made a distinction between the strategic and tactical factors, and the technological and organizational factors of implementation. Holland, Light and Gibson [34] grouped critical success factors into two categories: the strategic factors that span during the whole implementation project, and tactical factors that can be applied to particular parts of the project.

Loh and Koh [35] presented a framework of critical success factors in small and medium sized enterprises (SMEs), concluding that the most important factors are: project champion, project management, business plan and vision, and top management support [35]. Hustad and Olsen [36] concluded that SMEs have different challenges than larger organisations, mostly because of their limited resources and competencies [36].

Despite numerous implementation challenges and high implementation costs, ERP systems have become popular, and both small and large companies implement ERP systems in order to remain competitive. However, in some cases, ERP implementation can be very risky and, if organizations do not pay much attention to their limitations and requirements, results may be very unsatisfactory [12] [37].

According to Somers and Nelson [28], everyone who uses ERP systems needs to be trained on how they work and how they relate to business process, early on the implementation phase. Inadequate training and education could be considered as a significant reason for many ERP projects failures [10] [14]. Additionally, proper 'package' selection plays a vital role in successful implementation of ERPs, as it is one of the most important steps [10] [28].

During ERP implementation, business process reengineering should take place, in order to take full advantage of the new system [14] [34]. In addition, getting people educated, or trained, and keeping them informed throughout the whole implementation process should be amongst the first organisational priorities [28]. Moreover, through intensive guided learning, superior training and special knowledge activities, ERP consultants can help clients acquire the necessary knowledge for successful implementation [38]. Since users are an integral part of the attempted changes, the ones that will participate in the design and the implementation of new administration procedures must be sufficiently trained [34]. 
As demonstrated above, a significant number of studies on ERP implementation have been conducted. Many of these studies investigate the critical success factors for ERP implementation, and assist practitioners towards selecting the most suitable ERP software. Moreover, the studies of Al-Mashari, Al-Mudimigh and Zairi [14] and Umble, Haft and Umble [10] appear to be among the most cited papers in the ERP literature (423 and 636 citation respectively: data acquired from the 'Scopus' database, November 2015).

The present study conducted an analytical review of the ERP literature, and developed a conceptual framework that is a synthesis of previous contributions. More specifically, a list including the factors that have been used in order to predict ERP implementation success has been developed, while the most significant factors were, finally, incorporated in the proposed conceptual framework. In comparison with previous studies, the present empirical research does not only examine the antecedents, but, also, includes the outcomes of ERP implementation in its analysis.

\section{CONCEPTUAL FRAMEWORK}

Successful ERP implementation requires the coordination of many activities and a close cooperation between managers, employees, IT specialists, business analysts and consultants [39]. Therefore, any theoretical framework concerning ERP implementation effectiveness should include various dimensions in its analysis.

Based on the literature review analysis that was conducted prior to the development of the conceptual framework, the present study classified the antecedents of ERP implementation into four distinct categories (dimensions): (1) internal environment, (2) technology-related issues, (3) implementation team, (4) end-users. Additionally, each category (dimension) was determined with the use of several factors.

The selection of all research factors was a result of a specific procedure: (1) the Scopus database was used in order to identify previous studies concerning the antecedents of ERP implementation success (65 relevant studies were identified), (2) an extensive list, including the factors used in these studies, was constructed, (c) factors were given a significance index, based on the findings of each study, (d) each factor was categorized into one of the four pre-determined categories (dimensions), (e) the factors with the highest significance index in each category were, finally, selected.

The present study adopts a unique approach on the ERP literature. Instead of, only, examining the antecedents of ERP implementation success, the outcomes of the implementation procedure were, also, taken into consideration. Thus, an original three-dimensional conceptual framework (research model) was developed (see Fig. 1).

\section{A. Internal environment}

Successful implementation cannot be achieved, only by managers. Effective leadership is needed in order to achieve the desirable goals [35]. Organizations should, also, review their organizational culture and attitude towards change, before implementing an ERP system [40]. In this study, the dimension of "internal environment" includes four factors (top management support, business process reengineering, organizational culture, change management).

Top management support has been emphasized as a crucial factor in successful ERP implementation by previous studies [10] [14] [41]. Al-Mashari, Al-Mudimigh and Zairi [14] suggested that top management support should not only be offered during the initiation and facilitation stage, but throughout the entire ERP implementation process. Umble, Haft and Umble [10] claimed that successful ERP implementation requires the commitment and constant participation of top management. In a different case, the project is most likely to fail, or fail to deliver the full range of forecasted benefits [11] [12] [42].

Business process reengineering (BPR) has been, often, proposed as a critical success factor for ERP implementation [29]. Typically, BPR is carried out in order to restructure non-value-adding operations, reduce the complexity of business processes and eliminate inefficient processes [43]. Reengineering aims at making the necessary adjustments in order to take full advantage of the new processes offered by the ERP system [44]. Therefore, organizations should be willing to adjust their processes, so as to fit with the new software and minimize the degree of customization needed [34]. Most experts agree that software customization results in higher implementation costs and longer implementation period. Therefore, companies should keep the ERP package "as it is", as much as possible, and reengineer their business processes to conform to the package [45].

An organisational culture of shared values and common objectives is crucial for business success [46]. Organizations should built an organizational culture that is open to change [32], since openness to change plays a pivotal role in today's business environment. When organisational members have different cultures, beliefs and values, they, also, have different perceptions on various organizational changes [47]. In other words, organizational culture is a critical success factor for a project that requires significant changes [48]. Consequently, when the culture of an organisation is prone to change, ERP implementation is made quite easier.

Finally, Motwani, Subramanian and Gopalakrishna [27] argued that ERP projects that are supported by top management, but are not accompanied by adequate change management strategies are likely to fail. On the contrary, an implementation process backed with change management strategies and network relationships has been found to have a positive effect on implementation success [49]. Change management is a primary concern for many organizations involved in ERP implementation [50]. Research has shown that effective change management is critical to successful implementation [28]. Therefore, it is hypothesised:

H1: Internal environment has a positive impact on ERP implementation success. 


\section{B. Technology-related issues}

During ERP implementation, various technologicalrelated issues need to be addressed. More specifically, (a) the appropriate ERP package should be carefully selected [28]; (b) the overall support provided by the vendor should be taken under serious consideration [51]; and (c) the fit between the implemented system and the technological infrastructure of the organization should be examined [52]. The present study posits that all these dimensions (package selection, consultant (vendor) support, IT infrastructure) have a cumulative effect on ERP implementation success.

The selection of an ERP system, being among the first steps of implementation, appears as a critical factor [6]. After all, the package that will be selected will determine, to a great extend, the success of the project [10] [14]. Despite the fact that almost all ERP packages can be customized according to specific needs, customisation is very expensive and, usually, problematic [53]. Choosing the ERP package that best suits organisational needs and processes is critical to ensure successful implementation [6] [28].

However, no matter how important is to select a compatible ERP package, organizations should, also, select the appropriate vendor that will be able to offer full support. Troubleshooting is necessary for ERP implementation, so as to prepare for unexpected circumstances or, even, crises. This is an ongoing process, since the vendor (consultant) is obligated to assist in all stages on the implementation process [14] [32]. ERP adopting companies have to work closely with ERP vendors in order to determine possible software problems.

Finally, the appropriate IT infrastructure is necessary for the implementation of an ERP system [54]. Since most of ERP transactions are conducted in real-time, a reliable intranet, or local area network needs to be in place [32]. A company with a satisfactory level of IT infrastructure can be expected to implement new technologies, like ERP systems, more successfully than other companies, with low degree of IT readiness. From all the above, it is hypothesised:

H2: Technology has a positive impact on ERP implementation success.

\section{Implementation Team}

An effective implementation team is a key factor for every successful ERP project. The ERP team should consist of the best people in the organization [8] [22] [32]. At the same time, the implementation strategy is, also, critical, since it will assist the entire organization to adjust its business processes. In addition, a successful ERP implementation process requires excellent project management. Implementation team, the third antecedent of ERP implementation success, includes these three sub-factors (project team, project management, implementation strategy).

First of all, it must be made clear that an ERP implementation project involves all the departments of an organization [55]. According to Bhatti [54], the ERP project team includes: employees, managers, IT personnel, top management, the ERP vendor, and management consultants. Selecting the right employees to take part in the implementation process is critical for its success. The success of ERP projects is related to the skills, knowledge, abilities and experiences of project team members [55] [56].

As stated above, ERP implementation is a multi-level task, involving all business activities, and, often, requiring between one and two years of continuous effort [19] [20]. Therefore, an effective project management strategy should be in place in order to control the whole implementation process. ERP project management includes a clear definition of implementation objectives, the development of both work and resource plans, and a detailed tracking of project progress [34] [57].

Also, an ERP implementation strategy determines how the transfer from the legacy system to the new ERP system will be organised. Adopting an efficient strategy is of vital importance, since strategy sets the whole framework of implementation [58]. Without proper strategy, the whole implementation project is very likely to fail [58] [59].

It is hypothesised that all the above will have a cumulative positive effect on ERP implementation:

H3: Implementation team has a positive impact on ERP implementation success.

\section{End-Users}

Previous research has shown that no IT-based innovation can be successfully implemented without employee participation [60]. The attitude of end-users toward the ERP system has an impact on implementation success [61]. Characteristics of end-users have been identified as predictors of ERP implementation success, since the full benefits of the ERP system cannot be utilised until end-users are using it properly [10]. In this study, the dimension of "end-users" includes three factors (user involvement, training and education, employee skills).

User involvement is one of the most cited critical success factors in ERP implementation projects [14] [33]. Participation in the ERP implementation process raises the understanding of the new system and helps achieving better use [62]. Despite the level of training employees get during the implementation process [63], their involvement during the whole process is a very critical factor [10].

ERP requires a critical mass of employee knowledge in order to solve real problems within the company [18] [22] [64]. Everyone who uses the ERP system should be trained and educated on how the system works and how it can be used in everyday operations [28]. Organizations should provide training opportunities, on a regular basis, in order to improve the skills and knowledge of their employees. Sufficient training and education can increase the probability of ERP implementation success [32] [45].

Successful ERP implementation demands the constant cooperation of business experts, internal staff and external consultants, as well as the involvement of end-users in 
different project phases [32] [54]. Employee skills are very important, since they ensure that the technical and organizational aspects of the project run efficiently [34]. Without the appropriate skills of real system users, the ERP implementation is difficult to be successful.

It is hypothesised that all those factors will have an impact on ERP implementation success:

H4: End-users have a positive impact on ERP implementation success.

\section{E. Impact on organizational performance}

ERP implementation success can be measured using two different approaches. Some researchers have proposed quantitative financial measures (e.g. ROI, market share), while some others have proposed qualitative ones (e.g. decision making improvement) [31]. Dezdar and Ainin [11] argued that ERP implementation success depends on the evaluation of its actual users.

Shang and Seddon [43] stated that successful completion of ERP projects has a positive impact on organizational performance. That was supported by Ifinedo and Nahar [30], who claimed that the IS success model of Delone and McLean [65] leads to improvement in organizational performance, through three key antecedents: system quality, information quality and service quality. Consequently, the present study examined whether these three dimensions have an impact on organizational performance.

Information quality refers to the accuracy, timeliness, completeness and consistency of the information provided by the ERP system [31]. If the product (information provided by the ERP) is not delivered on time (timeliness) and does not conform to the needs of its customers (ERP users), then the latter will be dissatisfied and the company will lose business [66]. On the other hand, increased information quality will have a positive organizational impact, in terms of customer satisfaction and, thus, overall organizational performance will increase.

H5a: Information quality has a positive impact on organizational performance.

A well-designed ERP system is necessary for gaining organizational benefits. According to Chien and Tsaur [31], system quality is measured in terms of ease-of-use, functionality, reliability, flexibility and data quality. The expected benefits of system quality include cost reduction, enhanced performance and improved efficiency [67]. On the other hand, a system that is neither well designed nor userfriendly will, probably, create the risk of system failure [68].

$H 5 b$ : System quality has a positive impact on organizational performance.

Service quality is measured via the reliability, assurance and responsiveness of ERP service providers [31]. This dimension includes the overall quality of services that a particular Information System (IS) provides to an organisation [69]. According to Gorla and Wong [70], service quality is positively associated with organizational impact.

$H 5 c$ : Service quality has a positive impact on organizational performance.

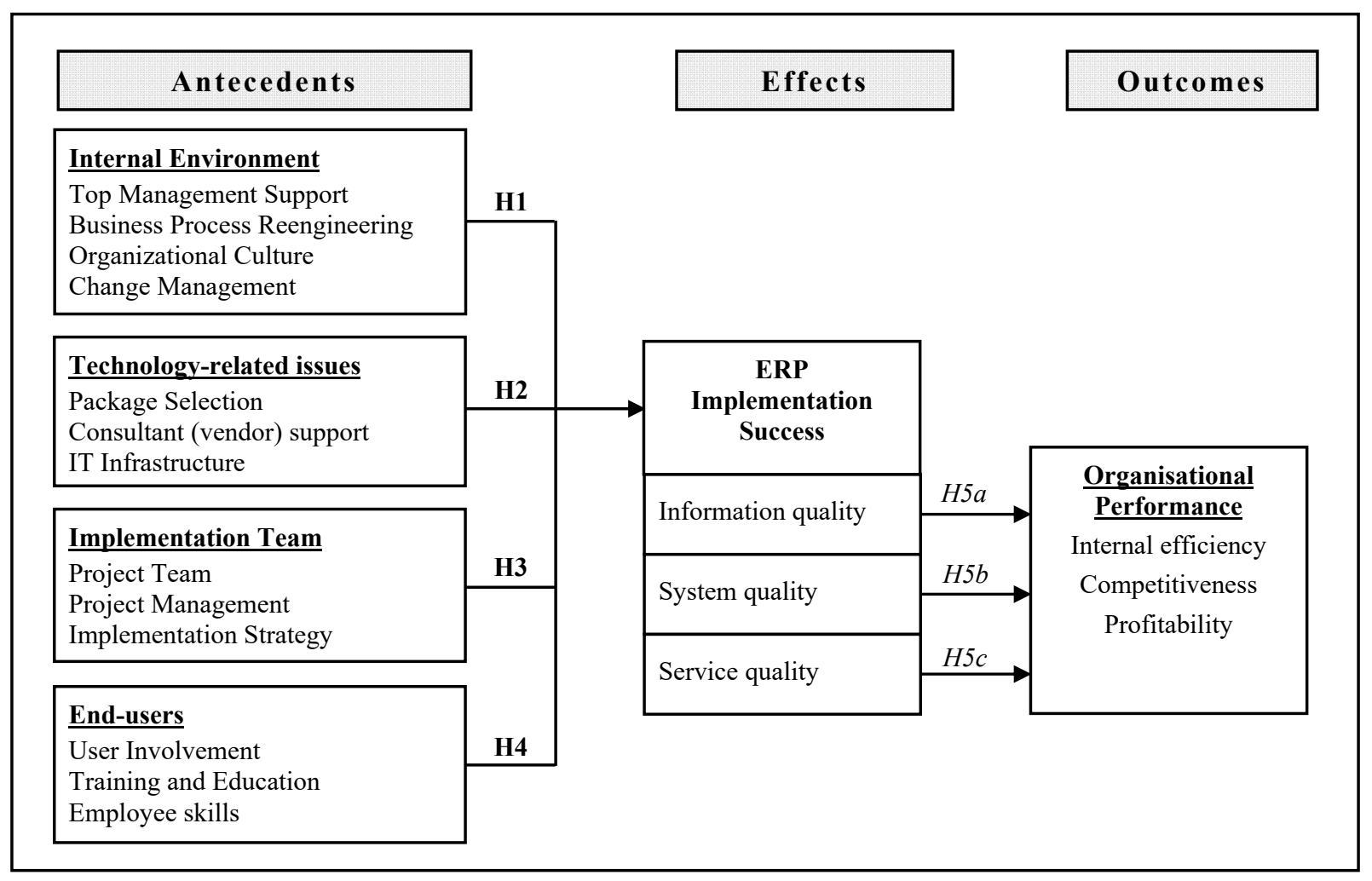

Fig 1. The Proposed Conceptual Framework of the study. 


\section{RESEARCH METHODOLOGY}

\section{A. Population of the study}

The proposed conceptual framework was tested on a sample of Greek companies that have implemented an ERP system. Data concerning the target population were obtained via the web sites of various ERP system providers operating in Greece. Totally, 617 companies that have implemented an ERP system were identified.

\section{B. Measurement}

A structured questionnaire, designed specifically for this empirical study, was used in order to collect the appropriate empirical data. All items used to measure the various research factors have been adopted by previous studies [6] [7] [10] [26] [27] [30] [31] [32] [41] [42] [45] [50] [54]. The five-point Likert scale was used for the measurement of all research factors. In total, ninety (90) items were used for the measurement of all research factors.

\section{Data collection}

IT managers were selected as key respondents, due to their experience and expertise. Questionnaires were sent after telephonic contact with the IT manager. After making all necessary arrangements, 467 questionnaires were distributed to 467 companies that agreed to participate in the survey. The research period lasted three months (October to
December 2015). 213 questionnaires were returned, but after conducting all necessary controls 204 were used for data analysis. The 204 returned questionnaires represent a very satisfactory response rate of $43,6 \%$.

\section{Validity and reliability}

During the construct validity test, each factor (see Table I) was evaluated (a) for its unidimensionality and reliability, (b) for its goodness of fit to the proposed model. The examination of the unidimensionality of each factor was conducted using Explanatory Factor Analysis (EFA). Moreover, Cronbach Alpha was used for estimating the reliability of the same factor. The evaluation of the goodness of fit of all factors was conducted using Confirmatory Factor Analysis (CFA). All tests concluded that, after the extraction of relatively few items, the scales used for the measurement of the research factors are valid and reliable. Table I presents the main results.

\section{EMPIRICAL RESULTS}

The conceptual framework was tested using the Structural Equation Modeling (SEM) technique. The estimation of the structural model was conducted with the Maximum Likelhood Estimation method [71].

After experimenting with various different models, it was decided that "organisational performance" should not be

TABLE I. VALIDITY AND RELIABILITY

\begin{tabular}{|c|c|c|c|c|c|c|c|c|}
\hline Factors & $\begin{array}{c}\text { Kaiser- } \\
\text { Mayer-Olkin }\end{array}$ & $\begin{array}{c}\text { \% of } \\
\text { Variance }\end{array}$ & $\begin{array}{c}\text { Cronbach } \\
\text { Alpha }\end{array}$ & $\begin{array}{c}\text { Normed } \\
\mathbf{X}^{2}\end{array}$ & C.R. & V.E. & CFI \\
\hline & \multicolumn{2}{|c|}{ Explanatory Factor Analysis } & \multicolumn{3}{|c|}{ Confirmatory Factor Analysis } \\
\hline Top Management Support & 0,834 & 61,769 & 0,875 & 2,24 & 0,69 & $57,7 \%$ & 0,97 \\
\hline Business Process Reengineering & 0,850 & 61,335 & 0,834 & 2,69 & 0,71 & $73,6 \%$ & 0,93 \\
\hline Organizational Culture & 0,741 & 56,448 & 0,737 & 3,29 & 0,86 & $78,2 \%$ & 0,89 \\
\hline Change Management & 0,818 & 75,910 & 0,891 & 3,45 & 0,87 & $71,6 \%$ & 0,91 \\
\hline $\begin{array}{c}\text { Second-Oder EFA-CFA: } \\
\text { Internal Environment }\end{array}$ & 0,692 & 55,674 & 0,734 & 2,78 & 0,76 & $58,6 \%$ & 0,94 \\
\hline Package Selection & 0,658 & 76,237 & 0,687 & 2,11 & 0,77 & $66,8 \%$ & 0,97 \\
\hline Consultant (vendor) support & 0,764 & 60,086 & 0,822 & 3,53 & 0,81 & $59,4 \%$ & 0,95 \\
\hline IT Infrastructure & 0,758 & 68,850 & 0,756 & 3,47 & 0,76 & $74,3 \%$ & 0,97 \\
\hline $\begin{array}{c}\text { Second-Oder EFA-CFA: } \\
\text { Technology-related issues }\end{array}$ & 0,702 & 73,111 & 0,839 & 2,26 & 0,74 & $76,8 \%$ & 0,91 \\
\hline Project Team & 0,724 & 54,850 & 0,775 & 2,71 & 0,81 & $76,9 \%$ & 0,91 \\
\hline Project Management & 0,775 & 62,502 & 0,850 & 2,33 & 0,76 & $66,3 \%$ & 0,97 \\
\hline Implementation Strategy & 0,620 & 60,615 & 0,773 & 3,29 & 0,74 & $74,3 \%$ & 0,97 \\
\hline $\begin{array}{c}\text { Second-Oder EFA-CFA: } \\
\text { Implementation Team }\end{array}$ & 0,707 & 71,544 & 0,801 & 3,22 & 0,81 & $83,7 \%$ & 0,97 \\
\hline User Involvement & 0,773 & 67,888 & 0,841 & 2,55 & 0,82 & $81,8 \%$ & 0,99 \\
\hline Training and Education & 0,705 & 60,649 & 0,779 & 3,55 & 0,84 & $67,3 \%$ & 0,91 \\
\hline Employee skills & 0,711 & 73,114 & 0,731 & 2,36 & 0,76 & $78,4 \%$ & 0,95 \\
\hline Second-Oder EFA-CFA: & 0,637 & 60,780 & 0,691 & 3,45 & 0,71 & $69,8 \%$ & 0,94 \\
\hline End-users & 0,762 & 62,175 & 0,796 & 2,14 & 0,83 & $79,3 \%$ & 0,97 \\
\hline Information Quality & 0,643 & 67,678 & 0,757 & 2,93 & 0,89 & $78,3 \%$ & 0,91 \\
\hline System Quality & 0,547 & 72,998 & 0,785 & 3,09 & 0,82 & $78,6 \%$ & 0,93 \\
\hline Service Quality & 0,773 & 79,219 & 0,865 & 2,53 & 0,73 & $79,1 \%$ & 0,97 \\
\hline Internal efficiency & 0,694 & 59,733 & 0,769 & 2,83 & 0,71 & $66,6 \%$ & 0,97 \\
\hline Competitiveness & 0,732 & 66,159 & 0,736 & 3,66 & 0,84 & $78,3 \%$ & 0,99 \\
\hline Profitability & & & & & \\
\hline
\end{tabular}


measured as coherent factor (structure), since the use of its various dimensions offered more in depth information about the investigated phenomenon. More specifically, as it can be seen in Fig. 2, the model that was finally examined includes three dimensions, with a total of ten factors.

In order to evaluate the fit of the overall model the chisquare value $\left(X^{2}=194,61\right)$ and the $p$-value $(p=0,0647)$ were estimated. These values indicate a good fit of the data to the overall model. However, the sensitivity of the $\mathrm{X}^{2}$ statistic to the sample size suggests the adoption of other measures for evaluating the overall model, such as the "Normed- $X^{2}$ " index $(2,95)$, the RSMEA index $(0,057)$ the CFI $(0,973)$ and the GFI $(0,967)$, that all indicate a good fit.

Fig. 2 demonstrates the overall model, along with the path coefficients. In general, the results reveal the mechanism through which the antecedents of ERP implementation are affecting the various dimensions of organizational performance. Both direct and indirect effects are being examined, thus, enhancing the understanding of the investigated phenomenon. The main findings of the study are summarised below:

- Overall, the empirical results confirmed that the research model has satisfactory predictive power, since it can significantly explain the variance of the main dependent factors of the present study ("internal efficiency" by $31 \%$, "internal competitiveness" by $51 \%$ and "profitability" by $35 \%$ ). Moreover, the variance of "system quality" is explained by $78 \%$, "service quality" is being explained by $32 \%$, and "information quality" by $21 \%$.
- While the relationship between several factors was not supported by the empirical data, partial support has been found for most of the hypotheses of the proposed model.

- More specifically, only one of the four antecedents included in the proposed conceptual framework (namely, "end-users") has an impact on all three dimensions capturing ERP implementation success (full support for Hypothesis 1). On the contrary, all other three antecedents have a direct impact on one dimension of ERP implementation success (partial support of Hypotheses 2, 3 and 4). More specifically, "internal environment" and "technology-related issues" have an impact on "system quality", while "implementation team" has an impact on "information quality".

- These findings underline the significance of the human factor in ERP implementation success. It seems that the endusers of the ERP system are the cornerstones for successful implementation. Implementing organizations need to take under serious consideration the involvement of end-user in the whole implementation process, provide training and education, while focusing on increasing their overall IT skills. Bradford and Florin [45], Dezdar and Ainin [22] found similar results. - Moreover, according to the empirical results, the antecedents of ERP implementation success should be considered as a coherent bundle of activities. Implementing companies should focus on all of these dimensions, since their simultaneous enhancement has a commutative impact on the effectiveness of the implementation process. Nevertheless, focusing on end-users should become the first priority.

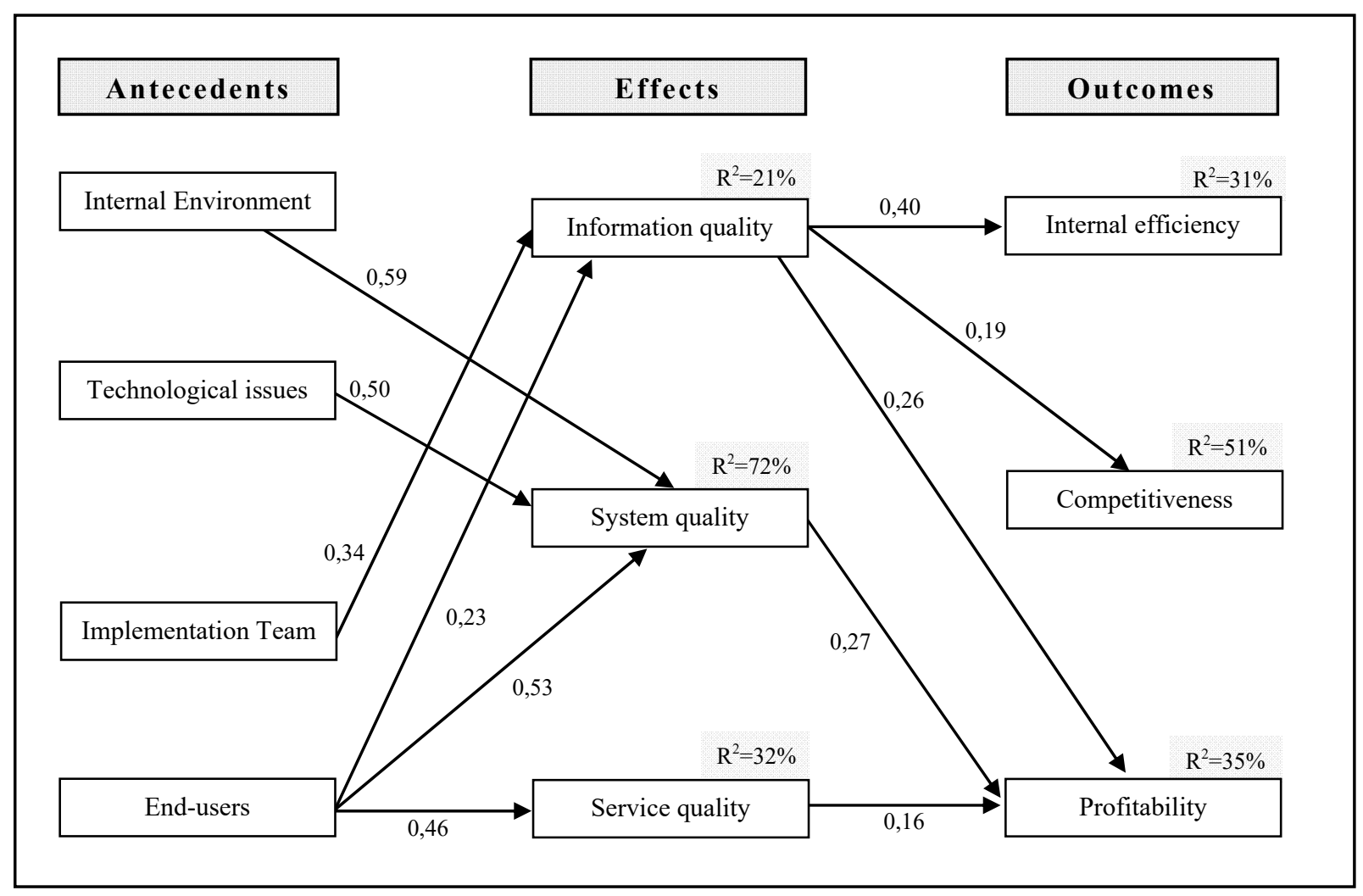

Fig. 2. Main empirical results (all paths are statistically significant). 
- The empirical results offer full support for hypothesis 5a, arguing that "information quality" has an impact on all dimensions measuring "organizational performance". Partial support is being offered for hypotheses $5 \mathrm{~b}$ and $5 \mathrm{c}$, since "system quality" and "service quality" have an impact on "profitability". Despite the little empirical research that has been conducted on the relationship between ERP and organizational performance, the very few existing studies support these results [16] [17] [18] [20].

- The significance of the three-dimensional approach (antecedents, effects and outcomes) introduced in the present study lies in the interrelationships between various research factors. For example, the proposed model explains $51 \%$ of the variance in "competitiveness" (outcome). As it can be seen on Fig. 2, there is only one factor having a direct positive effect on "competitiveness" ("information quality", $\mathrm{r}=0,19$ ). Despite that, two of the antecedents included in the model ("implementation team", and "end users") have an indirect effect on "competitiveness", through "information quality". Only through that mechanism, the $51 \%$ of explained variance can be justified.

- Therefore, based on the above, it can be concluded that enhanced competitiveness is a direct result of information quality, but, despite that, end-users of the ERP system and the team which is responsible for the implementation both have a significant strengthening effect on that relationship. Mapping down these complex relationships has been one of the most important contributions of the present study. Managers are urged to bear in mind the existence of these causal effects, since their main objective should be the enhancement of organizational performance.

\section{CONCLUSIONS}

The present study developed an conceptual framework that has never been used in the international ERP literature. Future studies can adopt the same approach, further highlighting the relationship between critical factors for ERP implementation success, ERP implementation, and organisational performance. Its main contribution lies on its implemented methodology and conceptualisation.

The empirical results enhance the understanding of the DeLone and McLean Information System (IS) success model [65] [69]. More specifically, a direct effect between "information quality", "system quality" and "service quality" and various measures of organisation performance has been established. On the contrary, the DeLone and McLean model [65] [69] argue that these dimensions have an indirect effect on organisational performance (through "user satisfaction" and "intention to use"). The support of a direct relationship, found in the present study, can be attributed to its conceptualization: the simultaneous examination of antecedents, effects and outcomes increases the explanatory power of the proposed model, offering a more complete picture of ERP implementation.
First and foremost, the empirical results highlight the significance of "end-users" in implementation effectiveness. Among all the antecedents of ERP implementation success, the dimension capturing the contribution of "end-users" on the whole process has the most significant effect. Previous studies [22] [41] have provided similar results, but very few have adopted such a methodological approach, using multiple factors for the measurement of each antecedent of ERP implementation success. For example, Zhang, Lee, Huang, Zhang and Huang [41] have, also, developed an ERP implementation success framework, but their empirical analysis was qualitative (case study research).

Secondly, since all four antecedents influence, each in a different degree, the three dimensions of implementation success, it is concluded that companies should focus on their collective enhancement. After all, all of these four factors (antecedents) have an indirect effect on organisational performance. For instance, the factor measuring the characteristics of the "implementation team" has an indirect impact on "internal efficiency", "competitiveness" and "profitability", through "information quality". Such a conceptual framework, taking under consideration both direct and indirect effects between antecedents and final outcomes, has very seldom been introduced in the ERP literature.

Thirdly, "information quality" appears as the most significant aspect of the implementation process, since it has a direct effect on all performance measures. According to previous studies [14], enhanced information quality during ERP implementation leads to increased performance. Information quality can help organizations choose different supply resources, hence, produce with lower costs and, therefore, develop competitive advantages, while increasing their competitiveness and internal efficiency.

The proposed model has adequate explanatory power, since it explains a significant percentage of the variance of all three main dependent factors. More specifically, it can predict $51 \%$ of the variance in business competitiveness, underlining the effect of ERP implementation on measures that previous studies have neglected [22] [43]. The enhanced power of the model lies in its three-dimensional approach, investigating both direct and indirect effects.

On a practical level, the present study offers a comprehensive list of factors having an impact on the successful implementation of an ERP system. Managers should focus on the enhancement of the most significant of these factors, identifying specific objectives for achieving successful implementation and increased performance. Finally, the present study underlines the mediating role of ERP implementation success in the relationship between various antecedents and final outcomes. It seems that such an approach can better describe the hypothesised relationships, since the effects of the four antecedents need to be translated into tangible benefits (information, system, and service quality) in order to have a positive impact on performance. 
The study is somehow limited by the poor definition of its population. This limitation is inherent to all studies of the field, since a complete list of ERP implementing companies is not easy to acquire. Further research is suggested with larger samples that would, probably, offer more information and strengthen the results of the present study. Moreover, it would be interesting to examine more factors and gather primary data from all company personnel, so as to achieve a more complete view of the subject under investigation.

\section{REFERENCES}

[1] I. Pawełoszek, "Approach to analysis and assessment of ERP system. A software vendor's perspective", IEEE Federated Conference on Computer Science and Information Systems (FedCSIS), pp. 14151426, 2015.

[2] M. Relich, "Knowledge acquisition for new product development with the use of an ERP database", IEEE Federated Conference on Computer Science and Information Systems (FedCSIS), pp. 1285$1290,2013$.

[3] J. Keller, and A. Heiko, "The influence of information and communication technology (ICT) on future foresight processes: Results from a Delphi survey", Technological Forecasting and Social Change, Vol. 85, pp. 81-92, 2014.

[4] A. Tenhiälä, and P. Helkiö, "Performance effects of using an ERP system for manufacturing planning and control under dynamic market requirements", Journal of Operations Management, Vol. 36, pp. 147164, 2015, http://dx.doi.org/10.1016/j.jom.2014.05.001.

[5] E. Galy, and M. J. Sauceda, "Post-implementation practices of ERP systems and their relationship to financial performance", Information \& Management, Vol. 51, No. 3, pp. 310-319, 2014, http://dx.doi.org/ 10.1016/j.im.2014.02.002.

[6] E. M. Shehab, M. W. Sharp, L. Supramaniam, and T. A. Spedding, "Enterprise Resource Planning: an integrative review", Business Process Management Journal, Vol. 10, No. 4, pp. 359-386, 2004, http://dx.doi.org/10.1108/14637150410548056.

[7] I. C. Ehie, and M. Madsen, "Identifying critical issues in enterprise resource planning (ERP) implementation", Computers in Industry, Vol. 56, No. 6, pp. 545-557, 2005, http://dx.doi.org/ 10.1016/j.compind.2005.02.006.

[8] M. M. Ahmad, and R. P. Cuenca, "Critical success factors for ERP implementation in SMEs", Robotics and Computer-Integrated Manufacturing, Vol. 29, No. 3, pp. 104-111, 2013, http://dx.doi.org/ 10.1016/j.rcim.2012.04.019.

[9] R. Rajnoha, J. Kádárová, A. Sujová, and G. Kádár, "Business Information Systems: Research Study and Methodological Proposals for ERP Implementation Process Improvement", Procedia-Social and Behavioral Sciences, Vol. 109, pp. 165-170, 2014, http://dx.doi.org/ 10.1016/j.sbspro.2013.12.438.

[10] E. J. Umble, R. R. Haft, and M. M. Umble, "Enterprise resource planning: Implementation procedures and critical success factors", European Journal of Operational Research, Vol. 146, No. 2, pp. 241257, 2003, http://dx.doi.org/ 10.1016/S0377-2217(02)00547-7.

[11] S. Dezdar, and S. Ainin, "Examining ERP implementation success from a project environment perspective", Business Process Management Journal, Vol. 17, No. 6, pp. 919-939, 2011, http://dx.doi. org/10.1108/14637151111182693.

[12] A. Amid, M. Moalagh, and A. Z. Ravasan, "Identification and classification of ERP critical failure factors in Iranian industries", Information Systems, Vol. 37, No. 3, pp. 227-237, 2012, http://dx.doi. org/10.1016/j.is.2011.10.010.

[13] J. Malaurent, and D. Avison, "From an apparent failure to a success story: ERP in China-Post implementation", International Journal of Information Management, Vol. 35, No. 5, pp. 643-646, 2015, http://dx.doi.org/10.1016/j.ijinfomgt.2015.06.004.

[14] M. Al-Mashari, A. Al-Mudimigh, and M. Zairi, "Enterprise resource planning: taxonomy of critical factors", European Journal of Operational Research, Vol. 146, No. 2, pp. 352-364, 2003, http://dx.doi.org/10.1016/S0377-2217(02)00554-4.
[15] X. Chan, Y. Y. Lau, and J. M. J. Ng, "Critical evaluation of ERP implementation on firm performance: a case study of AT\&T". International Journal of Logistics Systems and Management, Vol. 12, No. 1, pp. 52-69, 2012, http://dx.doi.org/ 10.1504/IJLSM.2012.047058.

[16] V. F. Dumitru, N. Albu, C. N. Albu, and M. Dumitru, "ERP implementation and organizational performance. A Romanian case study of best practices", Amfiteatru Economic, Vol. 15, No. 34, pp. 518-531, 2013.

[17] H. Ince, S. Z. Imamoglu, H. Keskin, A. Akgun, and M. N. Efe, "The Impact of ERP Systems and Supply Chain Management Practices on Firm Performance: Case of Turkish Companies", Procedia-Social and Behavioral Sciences, Vol. 99, pp. 1124-1133, 2013, http://dx.doi.org/ 10.1016/j.sbspro.2013.10.586.

[18] P. L. Liu, "Empirical study on influence of critical success factors on ERP knowledge management on management performance in hightech industries in Taiwan", Expert Systems with Applications, Vol. 38, No. 8, pp. 696-704, 2011, http://dx.doi.org/10.1016/j.eswa.2011.02.045.

[19] A. Madapusi, and D. D'Souza, “The influence of ERP system implementation on the operational performance of an organization", International Journal of Information Management, Vol. 32, No. 1, pp. 24-34, 2012, http://dx.doi.org/10.1016/j.ijinfomgt.2011.06.004.

[20] A. I. Nicolaou, and L. H. Bajor, "ERP systems implementation and firm performance", Review of Business Information Systems, Vol. 8, No. 1, pp. 53-60, 2011, http://dx.doi.org/10.19030/rbis.v8i1.4504.

[21] W. H. Tsai, K. C. Lee, J. Y. Liu, S. J. Lin, and Y. W. Chou, "The influence of ERP systems' performance on earnings management", Enterprise Information Systems, Vol. 6, No. 4, pp. 491-517, 2012, http://dx.doi.org/10.1080/17517575.2011.622414.

[22] S. Dezdar, and S. Ainin, "The influence of organizational factors on successful ERP implementation", Management Decision, Vol. 49, No. 6, pp. 911-926, 2011, http://dx.doi.org/10.1108/00251741111143603.

[23] W. Hwang, and H. Min, "Assessing the impact of ERP on supplier performance", Industrial Management \& Data Systems, Vol. 113, No. 7, pp. 1025-1047, 2013, http://dx.doi.org/10.1108/IMDS-01-2013-0035.

[24] H. W. Chou, Y. H. Lin, H. S. Lu, H. H. Chang, and S. B. Chou, "Knowledge sharing and ERP system usage in post-implementation stage", Computers in Human Behavior, Vol. 33, pp. 16-22, 2014.

[25] O. Zach, B. E. Munkvold, and D. H. Olsen, "ERP system implementation in SMEs: exploring the influences of the SME context", Enterprise Information Systems, Vol. 8, No. 2, pp. 309-335, 2014, http://dx.doi.org/10.1080/17517575.2012.702358.

[26] K. K. Hong, and Y. G. Kim, "The critical success factors for ERP implementation: an organizational fit perspective", Information \& Management, Vol. 40, No. 1, pp. 25-40, 2002, http://dx.doi.org/10. 1016/S0378-7206(01)00134-3.

[27] J. Motwani, R. Subramanian, and P. Gopalakrishna, "Critical factors for successful ERP implementation: exploratory findings from four case studies", Computers in Industry, Vol. 56, No. 6, pp. 529-544, 2005, http://dx.doi.org/10.1016/j.compind.2005.02.005.

[28] T. M. Somers, and K. Nelson, "The impact of critical success factors across the stages of enterprise resource planning implementations". In: Proceedings of the 34th Annual Hawaii International Conference on System Sciences, 2001, http://dx.doi.org/10.1109/HICSS.2001.927129.

[29] J. Ram, M. L. Wu, and R. Tagg, "Competitive advantage from ERP projects: examining the role of key implementation drivers", IEEE Engineering Management Review, Vol. 42, No. 3, pp. 36-53, 2014, http://dx.doi.org/10.1016/j.ijproman.2013.08.004.

[30] P. Ifinedo, and N. Nahar, "Quality, Impact and Success of ERP systems: a Study Involving Some Firms in the Nordic-Baltic Region", Journal of Information Technology Impact, Vol. 6, No. 1, pp. 19-46, 2006.

[31] S. W. Chien, and S. M. Tsaur, "Investigating the success of ERP systems: case studies in three Taiwanese high-tech industries", Computers in Industry, Vol. 58, No. 8-9, pp. 783-793, 2007, http://dx.doi.org/10.1016/j.compind.2007.02.001.

[32] F. F. Nah, J. L. Lau, and J. Kuang, "Critical factors for successful implementation of enterprise systems", Business Process Management Journal, Vol. 7, No. 3, pp. 285-296, 2001, http://dx.doi.org/10.1108/ 14637150110392782.

[33] J. Esteves, and J. A. Pastor, "Organizational and technological critical success factors behavior along the ERP implementation phases". In: Enterprise information systems VI. Ed. by I. Seruca, J. Cordeiro, S. Hammoudi, and J. Filipe, Springer Netherlands, pp. 63-71, 2006, http://dx.doi.org/10.1007/1-4020-3675-2_8. 
[34] P. Holland, B. Light, and N. Gibson, "A critical success factors mode for enterprise resource planning implementation". In: Proceedings of the 7th European Conference on Information Systems, pp. 273-297, 1999.

[35] T. Loh, and S. C. L. Koh, "Critical elements for a successful enterprise resource planning implementation in small-and medium-sized enterprises", International Journal of Production Research, Vol. 42, No. 17, pp. 3433-3455, 2004, http://dx.doi.org/10.1080/00207540410001671679.

[36] E. Hustad, and D. Olsen, "Critical Issues Across the ERP Life Cycle in Small-and-Medium- Sized Enterprises: Experiences from a Multiple Case Study", Procedia Technology, Vol. 9, pp. 179-188, 2013, http://dx.doi.org/10.1016/j.protcy.2013.12.020.

[37] A. A. Hawari, and R. Heeks, "Explaining ERP failure in a developing country: a Jordanian case study", Journal of Enterprise Information Management, Vol. 23, No. 2, pp. 135-160, 2010.

[38] E. T. G. Wang, C. C. L. Lin, J. J. Jiang, and G. Klein, "Improving enterprise resource planning (ERP) fit to organizational process through knowledge transfer", International Journal of Information Management, Vol. 27, No. 3, pp. 200-212, 2007, http://dx.doi.org/ 10.1016/j.ijinfomgt.2007.02.002.

[39] E. Alsene, "ERP systems and the coordination of the enterprise", Business Process Management Journal, Vol. 13, No. 3, pp. 417-432, 2007, http://dx.doi.org/10.1108/14637150710752326.

[40] E. W. T. Ngai, C. C. H. Law, and F. K. T. Wat, "Examining the critical success factors in the adoption of enterprise resource planning”, Computers in Industry, Vol. 59, No. 6, pp. 548-564, 2008, http://dx.doi.org/10.1016/j.compind.2007.12.001.

[41] Z. Zhang, M. K. O. Lee, P. Huang, L. Zhang, and X. Huang, "A framework of ERP systems implementation success in China: An empirical study", International Journal of Production Economics, Vol. 98, No. 1, pp. 56-80, 2005, http://dx.doi.org/10.1016/j.ijpe.2004.09.004.

[42] V. Gargeya, and C. Brady, "Success and failure factors of adopting SAP in ERP system implementation", Business Process Management Journal, Vol. 11, No. 5, pp. 501-516, 2005.

[43] S. Shang, and P. B. Seddon, "Managing process deficiencies with enterprise systems", Business Process Management Journal, Vol. 13, No. 3, pp. 405-416, 2007, http://dx.doi.org/10.1108/14637150710752317.

[44] S. C. Gardiner, J. B. Hanna, and M. S. LaTour, "ERP and the reengineering of industrial marketing processes: A prescriptive overview for the new-age marketing manager", Industrial Marketing Management, Vol. 31, No. 4, pp. 357-365, 2002, http://dx.doi.org/10. 1016/S0019-8501(01)00167-5.

[45] M. Bradford, and J. Florin, "Examining the role of innovation diffusion factors on the implementation success of enterprise resource planning systems", International Journal of Accounting Information Systems, Vol. 4, No. 3, pp. 205-225, 2003, http://dx.doi.org/10.1016/ S1467-0895(03)00026-5.

[46] T. Cadden, D. Marshall, and G. Cao, "Opposites attract: organisational culture and supply chain performance", Supply Chain Management: an International Journal, Vol. 18, No. 1, pp. 86-103, 2013, http://dx. doi.org/10.1108/13598541311293203.

[47] W. Ke, and K. K. Wei, "Organizational culture and leadership in ERP implementation”, Decision Support Systems, Vol. 45, No. 2, pp. 208218, 2008, http://dx.doi.org/10.1016/j.dss.2007.02.002.

[48] R. A. Jones, N. L. Jimmieson, and A. Griffiths, "The impact of organizational culture and reshaping capabilities on change implementation success: the mediating role of readiness for change", Journal of Management Studies, Vol. 42, No. 2, pp. 361-386, 2005, http://dx.doi.org/10.1111/j.1467-6486.2005.00500.x.

[49] A. Al-Ghamdi, "Change management Strategies and Processes for the successful ERP System Implementation: a Proposed Model", International Journal of Computer Science and Information Security, Vol. 11, No. 2, pp. 36-41, 2013.

[50] T. M. Somers, and K. G. Nelson, "A taxonomy of players and activities across the ERP project life cycle", Information \& Management, Vol. 41, No. 3, pp. 257-278, 2004, http://dx.doi.org/10. 1016/S0378-7206(03)00023-5.

[51] F. Cua, and S. Reames, "Big Vendor vs. Little Vendor: Managing the Enterprise Resource Planning (ERP) Project to Overcome the Laggard Sales Barrier", International Journal of Information Technology Project Management, Vol. 4, No. 2, pp. 50-74, 2013, http://dx.doi.org/ 10.4018/jitpm.2013040104.
[52] P. Katerattanakul, J. Lee, and S. Hong, "Effect of business characteristics and ERP implementation on business outcomes: An exploratory study of Korean manufacturing firms", Management Research Review, Vol. 37, No. 2, pp. 186-206, 2014.

[53] A. Sarfaraz, K. Jenab, and A. C. D’Souza, "Evaluating ERP implementation choices on the basis of customisation using fuzzy AHP”, International Journal of Production Research, Vol. 50, No. 23, pp. 7057-7067, 2012, http://dx.doi.org/10.1080/00207543.2012.654409.

[54] R. Bhatti, "Critical Success Factors for the Implementation of Enterprise Resource Planning (ERP): Empirical Validation”. In: The second International Conference on Innovation in Information Technology, 2005, Accessed at 17-11-2015 from: https://goo.gl/8Nual4.

[55] S. Newell, C. Tansley, and J. Huang, "Social capital and knowledge integration in an ERP project team: the importance of bridging and bonding", British Journal of Management, Vol. 15, No. 1, pp. 43-57, 2004, http://dx.doi.org/10.1111/j.1467-8551.2004.00405.x.

[56] C. C. Wei, and M. J. J. Wang, "A comprehensive framework for selecting an ERP system", International Journal of Project Management, Vol. 22, No. 2, pp. 161-169, 2004, http://dx.doi.org/10. 1016/S0263-7863(02)00064-9.

[57] H. Xu, P. J. Rondeau, and S. Mahenthiran, "Teaching case the challenge of implementing an ERP system in a small and medium enterprise: a teaching case of ERP project management", Journal of Information Systems Education, Vol. 22, No. 4, pp. 291-296, 2011.

[58] T. K. Chien, and M. S. Cheng, "The implementation strategy of key task for ERP activities". In: Proceedings of the 2014 IEEE International Conference on Industrial Engineering and Engineering Management (IEEM), Malaysia, pp. 1126-1130, 2014.

[59] E. F. Berger, "A generic model for selecting an ERP implementation strategy". In: Novel Methods and Technologies for Enterprise Information Systems, Ed. by F. Piazolo and M. Felderer. Springer International Publishing. Vienna: Austria, pp. 239-247, 2014.

[60] M. Chang, W. Cheung, C. Cheng, and J. Yeung, "Understanding ERP system adoption from the user's perspective", International Journal of Production Economics, Vol. 113, No. 2, pp. 928-942, 2008, http://dx. doi.org/10.1016/j.ijpe.2007.08.011.

[61] M. A. Krumbholz, J. Galliers, N. Coulianos, and N. Maiden, "Implementing enterprise resource planning packages in different corporate and national cultures", Journal of Information Technology, Vol. 15, No. 4, pp. 267-279, 2000, http://dx.doi.org/10.1080/02683960010008962.

[62] S. Dezdar, and S. Ainin, "Analysis of success measures in enterprise resource planning implementation projects", International Journal of Business Performance Management, Vol. 12, No. 4, pp. 334-353, 2011.

[63] L. Zhang, M. K. Lee, Z. Zhang, and P. Banerjee, "Critical success factors of enterprise resource planning systems implementation success in China", In: Proceedings of the 36th Annual Hawaii International Conference on System Sciences, 2003, http://dx.doi.org/ 10.1109/HICSS.2003.1174613.

[64] S. Dezdar, "Strategic and tactical factors for successful ERP projects: insights from an Asian country", Management Research Review, Vol. 35, No. 11, pp. 1070-1087, 2012.

[65] W. H. DeLone, and E. R. McLean, "Information Systems Success: the Quest for the Dependent Variable", Information Systems Research, Vol. 3, No. 1, pp. 60-95, 1992, http://dx.doi.org/10.1287/isre.3.1.60.

[66] P. M. Clikeman, "Improving Information Quality", Internal Auditor, Vol. 56, No. 3, pp. 32-33, 1999.

[67] M. Nofal, and Z. Yusof, "Integration of Business Intelligence and Enterprise Resource Planning within Organizations", Procedia Technology, Vol. 11, pp. 658-665, 2013.

[68] E. T. Wang, and J. H. Chen, "Effects of internal support and consultant quality on the consulting process and ERP system quality", Decision Support Systems, Vol. 42, No. 2, pp. 1029-1041, 2006.

[69] W. H. Delone, and E. R. McLean, "The Delone and McLean model of information systems success: a ten-year update", Journal of Management Information Systems, Vol. 19, No. 4, pp. 9-30, 2003, http://dx.doi.org/10.1080/07421222.2003.11045748.

[70] N. Gorla, T. M. Somers, and B. Wong, "Organizational impact of system quality, information quality, and service quality", The Journal of Strategic Information Systems, Vol. 19, No. 3, pp. 207-228, 2010, http://dx.doi.org/10.1016/j.jsis.2010.05.001

[71] N. K. Bowen, and S. Guo, Structural equation modeling, UK: Oxford University Press, 2011. 